\title{
PROTAGONISMO JUVENIL E MEDIDAS SOCIOEDUCATIVAS EM MEIO ABERTO: EXPERIÊNCIA EM OFICINAS TEMÁTICAS
}

\author{
PROTAGONISMO JUVENIL Y MEDIDAS SOCIOEDUCATIVAS EN \\ UN AMBIENTE ABIERTO: EXPERIENCIA EN TALLERES TEMÁTICOS \\ YOUTH PROTAGONISM AND SOCIO-EDUCATIONAL MEASURES \\ IN OPEN ENVIRONMENT: EXPERIENCE IN THEMATIC WORKSHOPS
}

\author{
Rafaela Rocha da Costa $^{1}$, Italo de Oliveira Guedes ${ }^{1}$ \\ e Maria de Fatima Pereira Alberto ${ }^{1}$
}

${ }^{1}$ Universidade Federal da Paraíba, João Pessoa/PB, Brasil

RESUMO: O objetivo deste relato é apresentar uma experiência sobre o desenvolvimento do Protagonismo Juvenil dos adolescentes e jovens que estão em cumprimento de medidas socioeducativas em meio aberto, a partir de Oficinas Temáticas realizadas no Centro de Referência Especializado de Assistência Social (CREAS). Para o desenvolvimento das oficinas foi construído um jogo de interpretação de personagem que teve a missão de revitalizar uma quadra de esportes. Partindo de um tema de interesse e de um jogo criado a partir da realidade concreta dos jovens, foi possível perceber o papel protagônico e o envolvimento dos jovens, que fomentou discussões sobre os serviços públicos e como poderiam se articular para modificar a realidade da quadra esportiva. Além disso, foi possível ampliar as discussões sobre outros direitos, como o direito ao esporte e ao lazer. Assim, trabalhar o protagonismo juvenil é reafirmar os adolescentes e jovens como sujeitos de direitos.

PALAVRAS-CHAVE: Medidas Socioeducativas; Adolescentes; Jovens; Protagonismo Juvenil.

RESUMEN: El propósito de este informe es presentar una experiencia sobre el desarrollo del Protagonismo Juvenil de adolescentes y jóvenes que están cumpliendo medidas socioeducativas en ambiente abierto, a partir de talleres temáticos realizados en el Centro de Referencia Especializado de Asistencia Social (CREAS). Para el desarrollo de los talleres se construyó un juego de rol con la misión de revitalizar una cancha deportiva. A partir de un tema de interés y un juego creado a partir de la realidad concreta de los jóvenes, se pudo percibir el papel protagonista y la implicación de los jóvenes, lo que propició discusiones sobre los servicios públicos y cómo se podían articular para cambiar la realidad de la cancha deportiva. Además, fue posible ampliar los debates sobre otros derechos, como el derecho al deporte y al esparcimiento. Así, trabajar con el protagonismo juvenil significa reafirmar a los adolescentes y jóvenes como sujetos de derechos.

PALABRAS CLAVE: Medidas socioeducativas; Adolescentes; Jóvenes; Protagonismo Juvenil.

ABSTRACT: This report aims to present an experience on the development of youth protagonism of teenagers and young people who are in compliance with socio-educational measures in open environment, based on Thematic Workshops held at the Specialized Reference Center for Social Assistance (CREAS). For the development of the workshops, a role-playing game was built with the mission of revitalizing a sports court. Starting from a topic of interest and a game created from the concrete reality of young people, it was possible to perceive the leading role and involvement of young people, which fostered discussions about public services and how they could articulate themselves to change the reality of the sports court. In addition, it was possible to expand discussions on other rights, such as the right to sport and leisure. Thus, working with youth protagonism means reaffirming adolescents and young people as subjects of rights.

KEYWORDS: Socio-educational measures; Teenagers; Young people; Youth protagonism. 


\section{Introdução}

O objetivo deste relato é apresentar uma experiência sobre o desenvolvimento do Protagonismo Juvenil dos adolescentes e jovens que estão em cumprimento de medidas socioeducativas em meio aberto, a partir de Oficinas Temáticas realizadas no Centro de Referência Especializado de Assistência Social (CREAS). O referido tema foi escolhido porque o desenvolvimento do Protagonismo se constitui como um dos objetivos das intervenções realizadas pela Política de Assistência Social.

A Tipificação dos Serviços Socioassistenciais (Ministério do Desenvolvimento Social e Combate à Fome [MDS], 2009, 2013, 2014), por exemplo, destaca a necessidade de proporcionar vivências que contribuam com a autonomia e o protagonismo social por meio de serviços para crianças e adolescentes com idades de 6 a 15 anos, para jovens de 15 a 17 anos e para jovens de 18 a 29 anos. Essas faixas etárias contemplam os adolescentes e jovens em cumprimento de Medidas Socioeducativas - que podem ir de 12 a 21 anos -; sendo assim, o protagonismo se revela como um tema importante a ser debatido em seus aspectos conceituais, práticos, políticos e pedagógicos, já que as medidas são socioeducativas. Ou seja, para além da responsabilização, devem ser educativas e contribuir com a construção de projetos de vida.

Rizzini, Sposati e Oliveira (2019) constataram que as medidas pautadas em uma perspectiva pedagógica, acompanhadas por profissionais que reconhecem os adolescentes e jovens em cumprimento de medidas socioeducativas como adolescentes e jovens de direitos, tiveram efeitos positivos como, por exemplo, a não reincidência. Além disso, os referidos autores afirmam que a compreensão dos processos precisa perpassar a interdisciplinaridade e intersetorialidade.

Prosseguindo com a discussão, segue uma breve contextualização sobre o surgimento do termo protagonismo e sobre seu desenvolvimento como categoria de ação. De acordo com Ferretti, Zibas e Tartuce (2004), no âmbito das políticas educacionais, a década de 90, no Brasil, foi um período de valorização da participação dos jovens e famílias na vida escolar por meio de documentos oficiais que difundiam o protagonismo juvenil no ensino médio, em particular as Diretrizes Curriculares Nacionais para o Ensino Médio. Foi nesse contexto, de considerar a participação ativa, que surgiu o termo "protagonismo". De acordo com Costa (2007), o termo tem origem grega e é formado a partir da junção de "proto", que significa o principal; e "agonismo", que significa lutador, ou seja, "proto + agonismo" significa lutador principal e foi sendo usado no teatro para se referir aos principais atores.

Ferretti et al. (2004) chegaram à conclusão de que o termo "protagonismo" vinha sendo utilizado para se referir às ações cidadãs e ao processo de preparação para executar ações desse tipo, que são planejadas e realizadas pelos jovens em diferentes contextos (escolar, social e político) em que há cooperação, compromisso e participação ativa no enfrentamento aos efeitos da desigualdade social. O protagonismo juvenil não deve ser entendido como um deslocamento das responsabilidades do Estado, família e sociedade civil para os jovens, pois representaria um tipo "perverso" de protagonismo que despolitiza a participação dos jovens.

Além disso, Ferretti et al. (2004) e Boghossian e Minayo (2009) chamam atenção para o fato de que as concepções sobre protagonismo são genéricas quando não consideram a realidade concreta dos jovens. Iulianelli (2003), por exemplo, apontava para o fato de 
o protagonismo juvenil vir se configurando como um discurso mais reproduzido pelos educadores sociais do que pelos próprios jovens; não que os educadores não possam se apropriar disso, mas seu papel é de mediar o processo por meio de ações educativas com os jovens. O protagonismo juvenil, como o próprio termo sugere, legitima-se nas ações e participação ativa dos jovens.

O protagonismo pode ser entendido como uma ação educativa que envolve os jovens na resolução de questões que perpassam seu cotidiano, na resolução de problemas concretos vivenciados por eles. Ou seja, os jovens atuam como atores principais (protagonistas) em alguma ação, atividade ou projeto que tenha o objetivo de solucionar problemas reais na escola, comunidade ou outros espaços mais ampliados (Costa, 2007). Complementando com as considerações de Boghossian e Minayo (2009), a participação ativa é aquela que envolve a modificação das estruturas sociais e econômicas, e não apenas situações pontuais e/ou eventuais, pois estas possuem apenas uma função adaptadora que se materializa por meio de práticas clientelistas e assistencialistas.

De acordo com Costa (2007), para exercitar o chamado "papel protagônico", é preciso possibilitar espaços e vivências, pautados em acontecimentos e não apenas nas palavras, em que se faça uso de recursos didáticos e pedagógicos diferentes dos tradicionais empregados em sala de aula. Marcilio, Thoman, Coscioni e Koller (2019) publicaram um relato sobre intervenções realizadas com adolescentes em medida socioeducativa, em que o protagonismo juvenil foi trabalhado a partir de atividades que envolviam a participação dos jovens em todo o processo. Esses autores constataram ao final que o envolvimento dos jovens evidenciava que as unidades eram carentes de atividades que favorecessem a criatividade e a participação, além de não considerar as necessidades e expectativas dos adolescentes.

Diante dessas considerações apresentadas e da importância atribuída ao protagonismo nos serviços socioassistenciais, justifica-se a relevância do tema da Oficina proposta para o âmbito do Centro de Referência Especializado em Assistência Social (CREAS), tendo como público os adolescentes e jovens em cumprimento de medidas socioeducativas em meio aberto, como a Liberdade Assistida (LA) e a Prestação de Serviços à Comunidade (PSC). A demanda pelas oficinas - que é uma atividade promovida mensalmente pelo serviço - surgiu das equipes técnicas dos CREAS diante da dificuldade de encontrar ministrantes, temas e/ou metodologias diversas. O motivo para buscar oficineiros(as) externos é que quando a oficina é conduzida por outros(as), a equipe - que já é reduzida - pode atender a outras demandas do serviço.

O convite para a realização das oficinas se deu durante a construção/coleta de dados para o estudo de uma tese de doutorado que analisa a trajetória de vida dos adolescentes e jovens em cumprimento de prestação de serviços à comunidade (PSC). Vislumbrou-se a realização de oficinas como uma forma de devolutiva da pesquisa ainda em seu processo de construção, um retorno aos serviços, aos jovens e à comunidade. De acordo com Minayo e Costa (2019), a pesquisa qualitativa envolve uma ética e um compromisso do pesquisador com os colaboradores da pesquisa, cujo retorno não precisa ser estritamente uma apresentação dos dados da pesquisa e suas conclusões, mas essa devolutiva pode se dar a partir da (re)formulação de políticas públicas ou mesmo por meio de algum recurso criativo construído pelo pesquisador. Por isso, foram construídas e conduzidas oficinas sobre Protagonismo Juvenil. 


\section{Método}

A proposta construída foi de realizar Oficinas - já que é uma atividade promovida mensalmente pelo CREAS - com duração de aproximadamente 60 minutos, podendo se estender a depender do desejo do grupo. Os primeiros 20 minutos foram destinados para apresentação da proposta, das pessoas presentes e para a explanação do conceito e relevância do Protagonismo Juvenil. O restante do tempo foi destinado à segunda parte da oficina, que tinha como finalidade colocar em prática o conhecimento a partir de uma situação concreta que precisava de resolução. Esse segundo momento foi estruturado como um jogo de interpretação de personagem, conhecido como RPG (role-playing game).

Os jogos de interpretação costumam ser praticados pelo público jovem, podendo ser de forma virtual ou presencial. De forma presencial costumam se dar por meio de uma ficha a ser preenchida pelos participantes com as informações sobre os personagens, que enfrentam uma missão. De acordo com Toledo (2015), o RPG mistura teatro e estratégia, favorecendo o raciocínio lógico, trabalho em grupo, as interações sociais, estímulo à leitura, tomada de decisões e desenvolvimento da autonomia. O RPG também foi escolhido como ferramenta diante de experiências pessoais que revelaram o caráter pedagógico do jogo.

E a ficha criada para a Oficina tinha os seguintes tópicos: Nome do Personagem, que deveria ser um nome fictício para não identificar os jovens; Facilidades e Dificuldades, ou seja, aquilo que o jovem considera que faz muito bem e aquilo que ele considera ter dificuldade e/ou quer melhorar; um quadro para a Vantagem que cada participante receberia no jogo por meio do lançamento de um dado; e um espaço para listar as Ações necessárias para a resolução da missão, que foi: Revitalizar a quadra de esportes abandonada do bairro, para que a comunidade tenha acesso ao esporte e ao lazer, um direito essencial. Foi construída uma ficha reunindo elementos de outras fichas disponíveis em meio digital (Pinterest, 2019), que resultou no modelo apresentado na Figura 1. 
Figura 1 - Ficha de RPG construída para a oficina sobre Protagonismo Juvenil

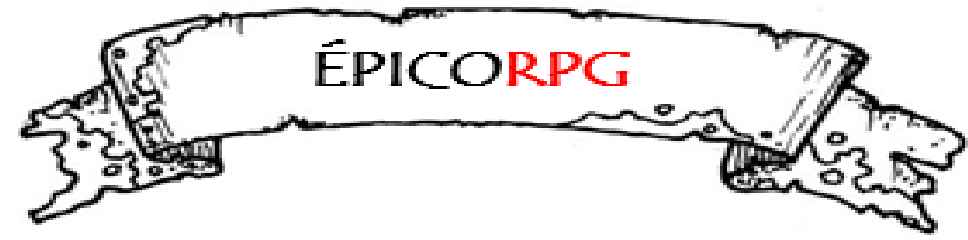

NOME DO PERSONAGEM:

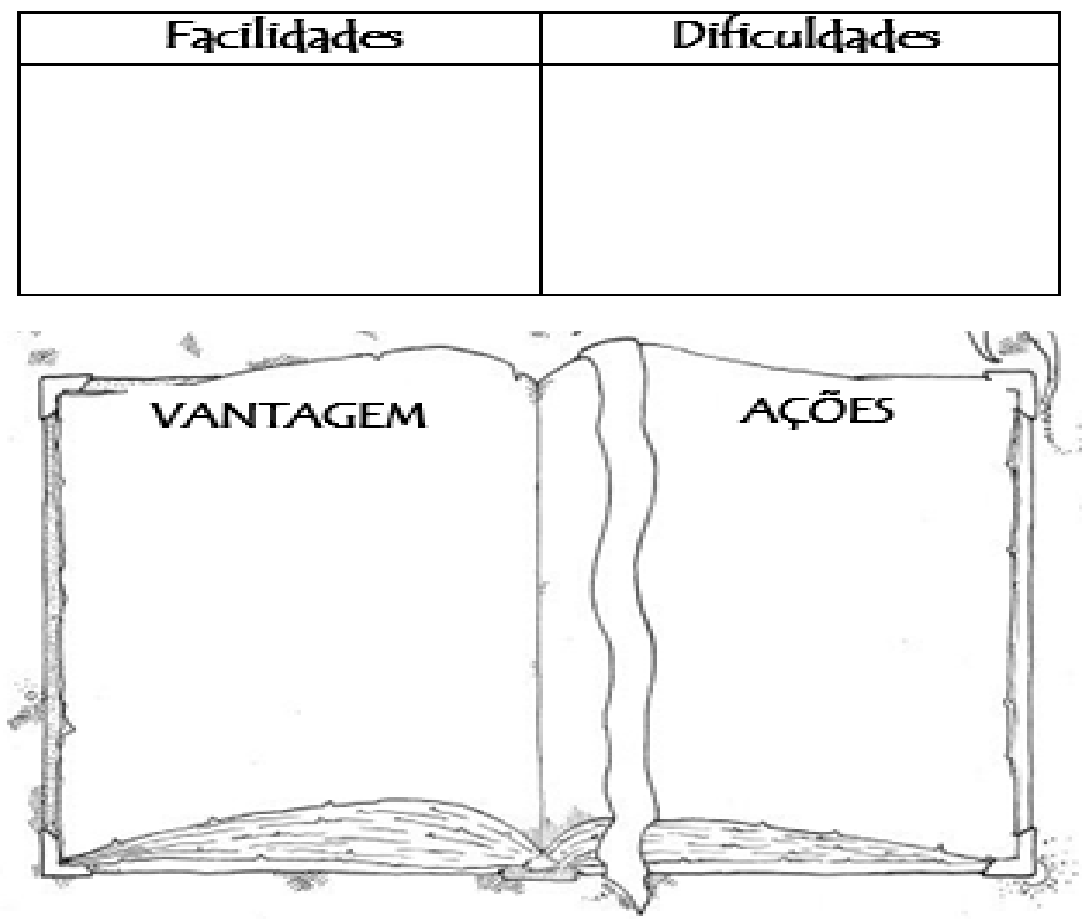

Fonte: Pinterest, 2019. Ficha adaptada a partir dos modelos disponíveis em Pinterest (2019).

Cada participante podia lançar o dado para ganhar as vantagens do jogo. As vantagens foram levadas impressas em papel e, à medida que eram sorteadas, iam sendo recortadas e coladas no espaço destinado para tal. As vantagens foram:

1. Ligações para o serviço de limpeza urbana do município;

2. Ligações para empresa de energia elétrica;

3. Parceria com escolinhas de futebol;

4. Fotos da situação da quadra;

5. Autorização para imprimir, no CREAS, os documentos e relatórios necessários à missão;

6. Autorização para ir com motorista do CREAS às instituições parceiras.

Assim, os materiais necessários para a realização das oficinas foram: fichas dos personagens, vantagens, cola, lápis, dados e fotos de quadras em condições degradantes. O local de realização das oficinas foram as salas de atividades em grupo dos CREAS, que solicitaram a oficina e contavam com uma mesa e cadeiras. 


\section{As oficinas}

Foram realizadas duas oficinas em diferentes CREAS. Na primeira só compareceram dois jovens, que aceitaram resolver a missão juntos. Foram sorteadas duas vantagens para cada, para que tivessem o total de quatro vantagens. Na segunda oficina estavam presentes oito jovens, além da mãe de um participante e a namorada de outro. Na segunda oficina foi possível formar dois grupos com quatro integrantes e foi sorteada apenas uma vantagem para cada integrante.

Antes da realização do RPG, a oficina começou com uma apresentação entre quem estava conduzindo e os jovens, que disseram nome, idade, medida socioeducativa que estavam cumprindo e há quanto tempo vinham sendo acompanhados pelo CREAS. A conversa foi iniciada falando sobre as medidas e sobre a relação com o tema da oficina. Alguns jovens colocaram que não entendiam o que era cada medida, o que foi prontamente explicado e contextualizado que o protagonismo é um aspecto a ser trabalhado com os jovens naquela política de referência. Para falar sobre protagonismo foi questionado sobre o que eles gostavam de assistir e falaram de séries e filmes, o que serviu para perguntar quem eram os atores principais da série e explicar o conceito de protagonista e diferenciar em relação ao protagonismo juvenil.

Um ponto importante tocado durante a explicação foi de que eles tinham os mesmos direitos de outros jovens, que o adolescente/jovem que pratica algum ato tipificado como infracional continua sendo sujeito de direitos e, como tal, podendo colocar em prática o protagonismo. Tal fala foi conduz da porque na pesquisa de doutorado anteriormente mencionada - que está sendo realizada com adolescentes e jovens em cumprimento de prestação de serviço à comunidade - alguns colaboradores falaram que não possuem mais direitos, que não podem escolher mais nada, que precisam aceitar as decisões dos outros.

Após a parte mais teórica, a proposta do jogo foi apresentada aos participantes; alguns se mostraram mais animados e outros mais relutantes, mas no decorrer da oficina todos participaram e interagiram. A missão em questão foi escolhida porque na referida pesquisa com adolescentes e jovens em cumprimento de PSC, o esporte - em particular o futebol - aparece como parte da trajetória de vida deles e como um dos interesses do presente e para o futuro. Alguns preenchiam os tópicos rapidamente e outros demoravam mais, a todo momento foi oferecida ajuda para o preenchimento e eles foram tirando as dúvidas sobre como escrever as palavras que queriam colocar.

Os nomes dos personagens variaram entre nome de jogadores de futebol e personagens de séries e filmes. Entre as Facilidades foram citadas: jogar futebol, dançar, falar muito e pilotar moto. Já as dificuldades mais citadas foram ler e escrever, mas também mencionaram a dificuldade de ficar em casa e um dos participantes listou jogar bola como uma dificuldade, o que gerou a reflexão por parte de um dos jovens de que depois de restaurar a quadra seria possível aprender a jogar nela.

$\mathrm{O}$ momento de sortear as vantagens era o mais empolgante, pois os participantes ficavam na expectativa do que conseguiriam para o grupo resolver a missão. Quando todos estavam com suas vantagens foi solicitado que cada grupo pudesse analisar todas as vantagens que tinha e quais ações faria primeiro. Quando envolvia ligar ou conversar com o representante de alguma instituição, era solicitado que simulassem a ligação e o diálogo era mediado pela pessoa que estava facilitando a oficina. 
Além das vantagens recebidas, e pensando nas facilidades dos membros do grupo, alguns ainda listaram outras instituições, tais como: as associações comunitárias, algumas empresas de comunicação televisiva e algumas secretarias do município. Foi um momento para refletir sobre as instituições que conheciam e como poderiam se articular para modificar a realidade da quadra esportiva. A oficina também tinha como eixo de discussão o direito ao lazer e ao esporte, que, de acordo com os participantes, não eram entendidos como um direito, mas como algo corriqueiro, para "ocupar a mente", como dizem.

Considera-se que o envolvimento dos participantes com a proposta da oficina se deu de forma participativa e protagônica em razão de envolver uma missão próxima da realidade deles, de uma atividade que realizam (jogar futebol) e demonstram interesse. Considerar essa realidade concreta é essencial para trabalhar o protagonismo juvenil, como já constatado por Ferretti et al. (2004), Costa (2007) e Boghossian e Minayo (2009).

Por vezes os participantes sugeriram formas mais rápidas de resolver a situação, propondo que eles mesmos realizassem a higienização das quadras ou os reparos, já que alguns faziam trabalhos de pedreiro. Nesses momentos eram resgatadas as concepções de protagonismo explanadas no início da oficina, destacando-se que o protagonismo juvenil precisa ser entendido como um processo politizado que perpassa as responsabilidades do Estado e de toda a sociedade, e, enquanto Estado, envolve os instrumentos públicos para a garantia de direitos e não por exploração da mão de obra daqueles adolescentes e jovens. Se não for assim, será um tipo de protagonismo "perverso", como colocado por Ferretti et al. (2004).

Ao final de cada oficina foi solicitado um feedback, um comentário sobre como foi participar daquela oficina. Todos falaram que foi diferente e foi bom por isso. Também sugeriram novos temas e formas de realizar as oficinas, para que sejam realizadas não somente com alguém falando sobre os temas, mas explanando-os a partir de diferentes recursos. Os temas sugeridos foram: os direitos dos jovens durante a abordagem policial, pois falaram que foram abordados com violência; cuidados com o meio ambiente; e, o mais mencionado, que as oficinas os preparassem para o mundo do trabalho, podendo ser sobre currículo, primeiro emprego ou mesmo sobre o Programa Jovem Aprendiz.

Dessa maneira, os próprios jovens evidenciaram a importância das políticas de formação profissional e a necessidade de sua ampliação, de modo a atingir ainda mais a juventude pobre, visto que este grupo é marcado, sobretudo, pela entrada precoce no mundo do trabalho, caracterizado pela informalidade, precarização das condições de trabalho e ausência de perspectiva de profissionalização e acesso a direitos sociais ou trabalhistas (Machado, 2018), como exemplificado no caso dos jovens que já trabalhavam como pedreiro antes do cumprimento da medida socioeducativa.

Sugeriram também que os temas das oficinas pudessem ser trabalhados por meio de filmes. Costa (2007) já destacava a importância de fazer uso de diferentes recursos para trabalhar o protagonismo juvenil e a experiência de Marcilio et al. (2019) em unidades de medidas socioeducativas apresenta a reflexão de que há uma carência de espaços que fomentem discussões a partir de recursos criativos e que estimulem a autonomia dos sujeitos envolvidos. 


\section{Algumas considerações}

O jogo de RPG se mostrou como uma ferramenta que permitiu colocar em prática o protagonismo juvenil à medida que foi pautado em um acontecimento próximo da realidade concreta dos jovens e a missão envolvendo o esporte motivou os participantes diante do fato de o futebol ser um evento significativo da trajetória de vida desses jovens. Trabalhar o protagonismo juvenil no âmbito das medidas socioeducativas se revelou como meio de trabalhar outros direitos e como processo que favorece a construção de espaços de reflexões que fomentem a compreensão de que o adolescente/jovem que praticou ato tipificado como infracional continua sendo sujeito de direitos.

Para além do esporte, vislumbra-se a potencialidade da dinâmica para exercitar o papel protagônico dos jovens em outras situações que fazem parte do seu cotidiano, já que difere dos métodos tradicionais de ensino. A ficha construída se revelou como um instrumento para identificar as potencialidades (aptidões) e as fragilidades dos participantes, que são aspectos trabalhados pela equipe no atendimento e acompanhamento dos adolescentes em cumprimento de medidas socioeducativas, podendo a ficha ser um instrumento pedagógico para tal finalidade.

A metodologia da oficina, como já sinalizado, foi construída para atender a demandas das unidades CREAS. Entrou-se em campo para fazer pesquisa, mas em seu processo foram requisitadas intervenções, que geraram reflexões para a própria pesquisa e para a prática com os adolescentes e jovens em cumprimento de medidas socioeducativas. Retornar para os atores e para a sociedade uma contribuição, para além dos dados e de um relatório técnico-científico, vem sendo um exercício de ética e compromisso social no fazer pesquisa. 


\section{Referências}

Boghossian, C. O. \& Minayo, M. C. S. (2009). Revisão sistemática sobre juventude e participação nos últimos 10 anos. Saúde e Sociedade, 18(3), 411-423. https://dx.doi.org/10.1590/ $\underline{\text { S0104-12902009000300006 }}$

Costa, A. C. G (2007). Protagonismo Juvenil: O que é e como praticá-lo. Recuperado de http://www.institutoalianca.org.br/Protagonismo Juvenil.pdf

Iulianelli, J. A. S. (2003). Juventude: construindo processos - o protagonismo juvenil. In P.Fraga, \& J. Iulianelli (Orgs.), Jovens em tempo real (pp. 54-75). Rio de Janeiro: DP\&A.

Ferretti, C. J., Zibas, D. M., \& Tartuce, G. L. (2004). Protagonismo Juvenil na Literatura Especializada e na Reforma do Ensino Médio. Cadernos de Pesquisa, 3(122), 41 1-423. Recuperado de http://www.scielo.br/scielo.php? script $=$ sci arttext\&pid=SO100-15742004000200007\&ln $\mathrm{g}=\mathrm{en} \& \mathrm{nrm}=\mathrm{iso \& t \operatorname {lng } = \mathrm { pt }}$

Machado, P. H. S. S. (2018). A condição juvenil periférica: notas introdutórias para entender a juventude no capitalismo dependente. REBELA-Revista Brasileira de Estudos Latino-Americanos, 8(3), 516-518. Recuperado de https://rebela.emnuvens.com.br/pc/article/view/408

Marcilio, F. C. P., Thoman, S., Coscioni, V., \& Koller, S. H. (2019). Protagonismo juvenil no contexto da medida socioeducativa: um relato de experiência. Revista da SPAGESP, 2O(1), 69-81. Recuperado de http://pepsic.bvsalud.org/scielo.php? script=sci arttext\&pid=S1677$\underline{-29702019000100006 \& \operatorname{lng}=p t \& t \operatorname{lng}=p t .}$

Minayo, M. C S. \& Costa, A. P. (2019). Técnicas que Fazem Uso da Palavra, do Olhar e da empatia: Pesquisa Qualitativa em Ação. Portugal: Ludomedia; São Paulo: Hucitec Editora.

Ministério do Desenvolvimento Social e Combate à Fome - MDS. (2009). Tipificação Nacional de Serviços Socioassistenciais: Documento Base - Fichas de Serviços. Secretaria Nacional de Assistência Social. Brasília: Autor.

Pinterest. (2019). RPG Fichas. Recuperado de https://br.pinterest.com/anubisescriba/ rpg-fichas/

Rizzini, I., Sposati, A., \& Oliveira, A. C. (2019). Adolescência, direitos e medidas socioeducativas em meio aberto. São Paulo: Cortez.

Toledo E. A. (2015). RPG como Estratégia de Ensino: Uma Proposta para o Ensino de Profissões. Universidade Estadual do Centro-Oeste. Paraná: Guarapava. Recuperado de http:// www.diaadiaeducacao.pr.gov.br/portals/cadernospde/pdebusca/producoes pde/2014/2014 unicentro ped pdp elizete da aparecida toledo.pdf 


\section{RAFAELA ROCHA DA COSTA \\ https://orcid.org/0000-0002-6148-0787}

Mestra e Doutoranda pelo Programa de Psicologia Social da Universidade Federal da Paraíba (UFPB). Docente do curso de Psicologia na Universidade do Estado de Minas Gerais, Unidade Divinópolis.

E-mail: rafaelarer@gmail.com

\section{ITALO DE OLIVEIRA GUEDES \\ https://orcid.org/O000-0001-7491-7266}

Mestre em Psicologia Social pelo Programa de Pós-graduação em Psicologia Social da Universidade Federal da Paraíba (UFPB). Integrante do Núcleo de Pesquisas e Estudos sobre o Desenvolvimento da Infância e Adolescência (NUPEDIA).

E-mail: italo_guedes@,hotmail.com

\section{MARIA DE FATIMA PEREIRA ALBERTO https://orcid.org/0000-0003-2515-9571}

Mestra em Serviço Social pela Universidade Federal da Paraíba (1991) e doutorado em Sociologia pela Universidade Federal de Pernambuco (2002). Professora Titular da Universidade Federal da Paraíba, do Programa de Pós-Graduação em Psicologia Social (mestrado e doutorado). Coordenadora do Núcleo de Estudos e Pesquisas sobre o Desenvolvimento da Infância e Adolescência (NUPEDIA).

E-mail: jfalberto89@gmail.com

\begin{tabular}{|c|c|}
\hline Histórico & $\begin{array}{l}\text { Submissão: 14/03/2020 } \\
\text { Revisão: 15/06/2020 } \\
\text { Aceite: } 25 / 06 / 2020\end{array}$ \\
\hline $\begin{array}{l}\text { Contribuição } \\
\text { dos autores }\end{array}$ & $\begin{array}{l}\text { Concepção: R.R.C. } \\
\text { Coleta de dados: R.R.C. } \\
\text { Análise de dados: R.R.C., I.O.G. e M.F.P.A. } \\
\text { Elaboração dlo manuscrito: R.R.C. e I.O.G. } \\
\text { Revisões críticas de conteúdo intelectual importante: } \\
\text { R.R.C., I.O.G. e M.F.P.A. } \\
\text { Aprovação final do manuscrito: M.F.P.A. }\end{array}$ \\
\hline $\begin{array}{l}\text { Aprovação, ética } \\
\text { e consentimento }\end{array}$ & $\begin{array}{l}\text { A experiência relatada faz parte da pesquisa de doutorado desenvolvida } \\
\text { pela primeira autora, aprovada pelo Comitê de Ética em Pesquisa do } \\
\text { Centro de Ciências da Saúde da Universidade Federal da Paraíba - CCS/ } \\
\text { UFPB, com CAAE } 11394719.4 .0000 .5188\end{array}$ \\
\hline Financiamento & $\begin{array}{l}\text { A primeira autora e o segundo autor eram bolsistas CAPES no momento } \\
\text { da realização das oficinas relatadas e da concepção da ideia do artigo. } \\
\text { A terceira autora era bolsista produtividade em pesquisa do CNPq, nível } 1 \mathrm{D} \text {. }\end{array}$ \\
\hline
\end{tabular}

